\title{
LA FILOSOFIA CRISTIANA MEDIEVAL: PANORAMA DE LOS ESTUDIOS HISPÁNICOS (SIGLO XX)
}

\author{
José Ángel García Cuadrado \\ Universidad de Navarra
}

\section{RESUMEN}

Se expone una visión panorámica de las principales obras y autores que han estudiado la filosofía medieval cristiana a lo largo del presente siglo. Se ofrece también una breve información sobre los medievalistas extranjeros que han estudiado la filosofía cristiana medieval en la península ibérica.

\begin{abstract}
A panoramic vision of the main Twenty Century Spanish works of investigation and authors who have studied Medieval Christian Philosophy. A brief exploration about foreign writings on the Hispanic Christian Philosophy in the Middle Ages has also been provided.
\end{abstract}

En el presente trabajo trataré de realizar una condensada síntesis de los principales estudios hispánicos sobre la filosofía medieval cristiana realizados a lo largo del siglo XX. La tarea no se presenta ciertamente exenta de problemas, siendo el primero de ellos el de la delimitación del objeto de estudio. En efecto, el análisis de este periodo requiere una serie de delimitaciones temporales por un lado, e histórico-culturales por otro.

La primera delimitación es la temporal. Como apunté anteriormente, la exposición se centrará principalmente en aquellos autores contemporáneos dedicados al estudio de la filosofía medieval, hispánica o no hispánica. Se trata, por tanto, de ofrecer una panorámica de los principales medievalistas del presente siglo. Sin embargo, los límites de la Edad Media aparecen especialmente difusos en la investigación medievalista de nuestro país. Así algunos autores suelen incluir los estudios sobre san Agustín, Boecio y san Isidoro dentro del ámbito medieval, ${ }^{1}$ mientras que otros prefieren fijar el límite en el siglo XII, con la labor de los traductores de obras árabes. Tampoco la fecha de conclusión del periodo medieval parece clara, pues no podemos hablar con propiedad de fin de la Edad Media, al menos en el ámbito hispano, hasta 
bien adentrados en el siglo XV; incluso algunos autores incluyen también a los teólogos de la «Segunda Escolástica», alargándose así el estudio hasta los siglos XVI y XVII.

En segundo lugar, fijaré mi exposición en la filosofía cristiana. Como es bien conocido, la noción de filosofía cristiana resulta asímismo problemática, suscitando todavía hoy no pocas controversias entre las diversas escuelas. ${ }^{2}$ En estos últimos años se ha reabierto el debate en una serie de artículos del medievalista Van Steenberghen y el profesor García López. ${ }^{3}$ No es este el momento oportuno para abordar la cuestión en toda su complejidad. Sin embargo, parece un hecho comúnmente aceptado que, al menos desde una perspectiva estrictamente históri$\mathrm{ca}$, la filosofía medieval occidental nos resultaría difícilmente comprensible sin considerarla íntimamente ligada al cristianismo. En efecto, el intento de armonización entre el saber racional y la fe, entre Filosofía clásica y Teología, así como el deseo de una profundización racional en el misterio revelado son necesarios para comprender de forma global el pensamiento medieval de estos siglos. ${ }^{+}$Por esta razón, entre los medievalistas, resultará difícil en ocasiones distinguir rígidamente entre historiadores de la filosofía y de la teología medieval.

El término «cristiano» aquí utilizado obedece más bien a una denominación histórico-cultural característica de nuestra península. Durante el periodo medieval coexistieron tres culturas bien diferenciadas en la península ibérica: la cultura musulmana, la judía y la cristiana. Así, pues, con el adjetivo «cristiana» me referiré a la filosofía proveniente de esta cultura para distinguirla de la musulmana y de la judía. No obstante, la distinción efectiva entre ellas resultará a veces difícil de realizar, pues en algunas ocasiones la convivencia geográfica se realizó de modo pleno y las mutuas relaciones e influencias fueron notables.

La última delimitación del objeto de mi exposición resulta no menos conflictiva que las anteriores. Me refiero a la expresión «filosofía española». No se trata tanto de una denominación meramente geográfica, sino de un calificativo de alcance mucho mayor, como se puso bien de manifiesto al iniciarse la polémica acerca de la «ciencia española» a finales del siglo pasado.

La discusión sobre la existencia o no de una «filosofía española» se remonta a los últimos años del siglo XIX cuando Menéndez Pelayo reivindicó la existencia de un pensamiento filosófico hispánico, con unos caracteres propios y originales, frente a las posturas de autores como Manuel de Revilla, Nicolás Salmerón o José del Perojo por un lado, y Alejandro Pidal con Joaquín Fonseca por otro. Estos autores, bajo perspectivas muy diversas, negaron la exis-

2 Una excelente exposición histórica del problema de la filosofía cristiana, desde una postura gilsoniana se encuentra en Livi, A., Étienne Gilson. Filosofía cristiana e idea del límite crítico, Eunsa. Pamplona 1970.

3 Para una síntesis de esta discusión, cfr. García López. J., «Diálogo con Van Steenberghen a propósito de la Filosofía cristiana», en Scripta Fulgentina, I (1991/2), pp. 69-94. Resulta significativo que también desde el ámbito anglosajón se haya reabierto esta controvertida cuestión; cfr. Plantinga, A.. «Advice to Christian Philosophers», en Faith and Philosophy; 3 (1984), pp. $253-271$ y D'Andrea, Th., «Rethinking the Christian Philosophy Debate: An Old Puzzle and Some New Points of Orientation», en Acta Philosophica, 1 (1992/2), pp. 191-214.

4 Nos remitimos entre otros a los ya clásicos trabajos de Gilson. É., La filosofía en la Edad Media. Desde. los origenes patristicos hasta el fin del siglo XIV, Gredos, Madrid 1972; Gilson. É., El espiritu de la filosofía medielal, Rialp, Madrid 1981; Pieper, J., Filosofia medieral y mundo moderno, Rialp, Madrid 1978. 
tencia de una filosofía propia de la cultura española; los primeros, por infravalorar la existencia y alcance de los pensadores hispánicos y los segundos, por no reconocer más que la existencia de una única filosofía verdadera: la filosofía escolástica. ${ }^{5}$

Frente a los primeros, Menéndez Pelayo redescubre obras y autores hispanos, olvidados o desconocidos; por otro lado muestra la existencia de corrientes filosóficas típicamente españolas, como son el lulismo, el vivismo o el suarismo. Frente a los segundos no duda en afirmar que en la aportación hispánica al pensamiento universal aparecen de modo indeleble las características propias del pensamiento español.

La propuesta de Menéndez Pelayo fue recogida, ya a comienzos del siglo XX, por su discípulo Adolfo Bonilla y San Martín que realizó el plan de una «Historia de la Filosofía española», desde su constitución como tal, hasta el siglo XIX. Él mismo inició la ingente tarea con la publicación, en 1911, de dos volúmenes que cubrían los siglos VII al XII. Sólo en 1939 continuó adelante el plan de Bonilla con la publicación de los volúmenes de Carreras Artau (filosofía medieval cristiana), Cruz Hernández (filosofía musulmana) y Marcial Solana (filosofía renacentista).

De manera muy sucinta recordaré ahora algunas de las figuras más representativas de la filosofía cristiana peninsular durante la Edad Media. En el siglo XII, la península ibérica cobró importancia desde el punto de vista filosófico gracias a la labor llevada a cabo por los traductores de diversos centros culturales como Toledo: de esta forma, autores como Domingo Gundisalvo y Juan Hispano son objeto de estudio de medievalistas españoles y extranjeros.

En los siglos XIII y XIV el protagonismo que nuestra Península había alcanzado durante el siglo XII, se desplaza hacia París, en cuya universidad aparecieron los grandes maestros del pensamiento medieval: Tomás de Aquino, Alberto Magno, Duns Escoto, Guillermo de Ockham,... No obstante, diversos filósofos hispanos deben ser nombrados, aunque más o menos relacionados con el ámbito intelectual parisino: Pedro Hispano (comentador de Aristóteles y autor del Tractatus que fue el manual de lógica en las universidades europeas hasta el siglo XVI); los dominicos Raimundo Martí (discípulo de san Alberto y compañero de santo Tomás), san Vicente Ferrer, el lógico Pedro Alfonso, Juan de Monzón y. Nicolás Eymerich. Entre los franciscanos destacan Gonzalo de Balboa (maestro de Duns Escoto), Antonio Andrés, Guillermo Rubió, Pedro Tomás y Pedro Castrovol, éste último entrado ya el siglo XV.

Mención aparte merece sin duda la original e ingente producción de Ramón Llull. Su originalidad proviene fundamentalmente de su espíritu autodidacta que le llevó a la lectura de Platón, san Agustín, san Anselmo, Ricardo de San Victor y a la de lógicos árabes; pero su formación filosófica no se realizó en París ni en ningún otro centro intelectual europeo. Junto a

5 Para una detallada descripción histórica de la polémica pueden consultarse entre otras las obras de Fraile: G., Historia de la Filosofia española (I). Desde los origenes hasta el siglo XVII, BAC; Madrid 1985, pp. 3-30; y Abellán. J.L., Historia crítica del pensamiento español (I). Metodología e introducción histórica, Espasa-Calpe: Madrid 1979. pp. 41-59. 
Llull aparece también la polémica figura del médico-filósofo Arnau de Vilanova que, junto a Llull, continúa atrayendo la atención de los medievalistas europeos.

En el otoño del pensamiento medieval, aparecen autores hispánicos como Ramón Sibiuda (dentro del lulismo) y otros que desempeñaron su labor docente en París (Jacobo Magnus, Alvaro Tomás, Gaspar Lax, Juan Lorenzo Celaya) y en Salamanca (Juan de Oria y Alonso de Córdoba entre otros). En España la prolongación de las escuelas medievales en el seno de las universidades propició el florecimiento de la Escolástica a lo largo de los siglos XVI y XVII. Es la época de pensadores, centrales en la filosofía peninsular, como Francisco Vitoria, Melchor Cano, Domingo de Soto, Juan de Santo Tomás, Domingo Báñez, y más tarde, Francisco Suárez. De este modo, la labor intelectual hispánica recobró protagonismo en el contexto del pensamiento occidental.

Dejando abierta la discusión acerca de cuales serían concretamente los caracteres peculiares de la filosofía española, nos parece indudable, por el número e importancia de los autores apenas mencionados, que el pensamiento filosófico desarrollado en la España cristiana durante la Edad Media cuenta con una entidad propia, justificándose así el interés suscitado en nuestra península y fuera de ella, por parte de los medievalistas e historiadores de la Filosofía. Por lo demás se ha llegado a consolidar, a lo largo del presente siglo, una notable tradición medievalista en nuestra península, si bien ciertamente menor que la ya existente en otros países europeos como Francia, Bélgica, Alemania o Italia, de antigua tradición.

\section{LOS ESTUDIOS DE FILOSOFÍA MEDIEVAL DESDE PRINCIPIOS DE SIGLO HASTA LA DÉCADA DE LOS CUARENTA.}

Esta tradición de medievalista entronca con la figura de Marcelino Menéndez Pelayo, el verdadero precursor de los estudios filosóficos hispanos. Su discípulo Adolfo Bonilla San Martín (1875-1926) es el que dará una configuración concreta a las investigaciones posteriores. Es él, en efecto, el que en 1904 llevó a cabo un primer plan de la historia de la filosofía española y el que comenzó la publicación, entre los años 1908-1911 de los dos primeros volúmenes de dicha historia, que abarcaba desde los orígenes del pensamiento hispánico hasta el siglo XII. La labor investigadora de Bonilla es, por lo tanto, clave para comprender lo que será después la historiografía medieval española del siglo XX.

Sólo en 1939 se pudo continuar la tarea de Bonilla San Martin, con la publicación de los dos volúmenes de los hermanos Carreras Artau. Sin embargo, este periodo de tiempo que media entre la publicación de la obra de Bonilla y la de Carreras Artau, no estuvo vacío de autores que dedicaran su atención a la filosofía medieval. La gran parte de los trabajos de investigación durante estos años recayó principalmente sobre las órdenes religiosas.

$\mathrm{Si}$ bien es cierto que no a todos los autores o estudiosos provenientes de las órdenes religiosas se les puede calificar de «medievalistas» en sentido estricto, sí podemos afirmar, en cambio, que al estudiar estos historiadores a los grandes maestros de sus respectivas órdenes 
contribuyeron a enriquecer sustancialmente las investigaciones de filosofía medieval en España, realizando una labor investigadora que se desarrollará posteriormente con la colaboración de otras instituciones. Los jesuitas publicaron la revista «Razón y Fe» (fundada en 1901); los dominicos, la «Ciencia Tomista» (iniciada en 1910); los padres franciscanos cuentan con «Estudios franciscanos» desde 1907, mientras que los agustinos continuaban con «La Ciudad de Dios» que había comenzado su andadura en 1887.

Entre los dominicos destacan Luis Alonso Getino (1877-1946), fundador de la revista «Ciencia Tomista». Su labor investigadora, sin embargo, no se centró especialmente en la filosofía medieval, aunque sí contribuyó de modo indirecto en los estudios sobre ella. Dedicó especial atención a la historia de la Orden de Santo Domingo y estimuló de este modo el desarrollo de los estudios medievales, como lo demuestran sus trabajos sobre el averroísmo teológico de santo Tomás, así como las aportaciones sobre las relaciones entre la Summa contra Gentiles de santo Tomás y el Pugio Fidei de Raimundo Martí. ${ }^{6}$ Asimismo, los trabajos del P. Vicente Beltrán de Heredia (1885-1973) suponen una importante contribución a la historia de la filosofía y teología españolas. Aunque tampoco se especializó en el pensamiento medieval, sus investigaciones sobre la influencia de santo Tomás en la filosofía española le hacen acreedor de nuestra mención. Por otro lado, a él debemos la exhumación de numerosos manuscritos de autores medievales que se encontraban olvidados en las bibliotecas españolas. No podemos dejar de mencionar a Venancio Diego Carro (1894-1972), que durante estos años publicó numerosos trabajos en la «Ciencia Tomista», dedicando especial atención a los autores Domingo de Soto, Francisco de Vitoria, Domingo Báñez y Pedro de Soto, siendo de particular interés su aportación sobre el derecho de gentes en los teólogos-juristas de Salamanca.

En esta visión panorámica es preciso deternerse en la obra del P. Santiago Ramírez (18911967), que pasa por ser uno de los más fidedignos intérpretes del pensamiento de santo Tomás de nuestro siglo. ${ }^{7}$ Cabe asignarle el mérito de haber vuelto a las fuentes tomistas para purificar la doctrina del Doctor Angélico de las adherencias que algunos comentadores habían introducido en el pensamiento original del Aquinate. Se pueden resumir en tres puntos las principales aportaciones de Ramírez. En primer lugar, la noción de analogía: entre los años 1921-22 publicó una serie de artículos en la revista la «Ciencia Tomista» (De analogia secundum doctrinam aristotelico-thomisticam) en los que realizaba una primera aproximación al estudio directo de la noción de analogía en santo Tomás, frente a las interpretaciones que nos han llegado a través de Cayetano. Posteriormente reelaboró estos artículos y fueron publicados en cuatro tomos, verdadera enciclopedia sobre el tema. El segundo punto original se sitúa en la interpretación del concepto de filosofía, como se observa en los artículos aparecidos en la misma revista en los años 1922 y 1923. En estos artículos sigue fielmente la doctrina tomista,

6 Las relaciones y mutuas influencias de la Summa contra Gentiles y el Pugio Fidei fue un tema de discusión entre los medievalistas hispanos; actualmente se suele admitir la tesis de Alonso Getino según la cual la influencia de la obra de Tomás de Aquino sobre la de Raimundo Martí fue decisiva.

7 Para un exposición del pensamiento de Ramírez puede consultarse la obra de López Quintás, A.. Filosofía española contemporánea. Temas y autores, BAC; Madrid 1970, pp. 371-377. 
pero se remite también a otros autores, clásicos o escolásticos. Sin embargo, esta obra quedó entonces inacabada y fue posteriormente terminada y publicada en dos tomos con el título De ipsa philosophia in universum secundum doctrinam aristotelico-thomisticam. En tercer lugar, -ya entre los años 1951 y 1963- destacan sus estudios sobre la filosofía del derecho en santo Tomás. En estos estudios acude de nuevo a las fuentes textuales para valorar desde allí las interpretaciones que Vitoria, Suárez y Soto hicieron de la doctrina del Angélico. De este modo, la contribución de Ramírez no se limita sólo a la filosofía del Aquinate, sino que se extiende también a la Segunda Escolástica. La extensa obra de Ramírez permanece aún parcialmente inédita. No se trata, en efecto, de un medievalista en sentido estricto, pero posiblemente ningún autor español contemporáneo ha llegado a conocer más a fondo el contenido y el espíritu de la doctrina de santo Tomás.

Entre los autores carmelitas de esta época cabe citar a Bartolomé María Xiberta i Roqueta (1897-1967), profundo conocedor de la obra de Guido de Terrara, así como de otros carmelitas del siglo XIV, como lo demuestra su principal obra: De scriptoribus scholasticis saeculi XIV ex ordine carmelitanum. A él debemos el examen crítico de muchos manuscritos medievales de ese siglo, y diversos estudios sobre santo Tomás. ${ }^{8}$

De la Orden franciscana tiene particular importancia la obra de Mariano Fernández García (1864-1940), medievalista del grupo de editores de Quaracchi, de Florencia. Gran conocedor del pensamiento de Duns Escoto, escribió el Lexicon Scotista (1910), editó las Disputationes oxonienses y la Grammatica speculativa (1902) del Doctor Sutil, y colaboró en la edición crítica del B.J. Duns Escoti Summa Theologiae, entre los años 1900-1903. ${ }^{9}$

Entre los agustinos hay que subrayar la ingente labor desarrollada por el P. Victorino Capánaga O.S.A.R. (1897), autor de las traducciones castellanas de las obras de san Agustín, así como de numerosísimos trabajos sobre el mismo autor y su influencia en el pensamiento medieval; ${ }^{10}$ y, por último, el trabajo ya clásico de Pedro Blanco-Soto (1873-1942), publicado en 1916, sobre Estudios de bibliografía luliana.

Fuera del ámbito de las órdenes religiosas mencionaré a Salvador Bové (1869-1915), cuya labor investigadora se encuentra estrechamente ligada al pensamiento de Ramón Llull. Fue fundador y director de la «Revista luliana» hasta su desaparición en 1905. Sin embargo, su campo de estudio se amplía al resto de la filosofía medieval como lo demuestra su obra sobre Santo Tomás de Aquino y el Descenso del entendimiento (Platón y Aristóteles armonizados por el Beato Raimundo Lulio), publicado en 1913, en donde propone la tesis de que el lulismo es un desarrollo y complemento del tomismo."

8 Sobre la obra de Xiberta, cfr. Ferrater Mora, J., Diccionario de Filosofía (III), Ed. Sudamericana, Buenos Aires 1969, p. 947.

9 Sobre la vida y obra de este autor puede consultarse Díaz Díaz, G.. Hombres y documentos de la filosofía española (III), CSIC, Madrid 1988, p. 183.

10 Sobre la obra de Capánaga. cfr. Díaz Díaz, G., Hombres y documentos de la filosofía española (II). pp. 116-122.

11 Nos quedarían por citar algunos trabajos interesantes de este periodo, como los de Francisco Sureda Blanes sobre Ramón Llull, o los artículos de Altés Escribá y Lorenzo Riber sobre Sibiuda. 
Algunos de los autores reseñados en los apartados anteriores han continuado posteriormente las investigaciones, como veremos a continuación. Agruparé los estudios por Órdenes religiosas, asociaciones y universidades.

\section{LOS ESTUDIOS MEDIEVALES DESDE LA DÉCADA DE LOS CUARENTA HASTA LA ACTUALIDAD}

El panorama de estudios medievales -sobre todo a partir de la década de los cuarenta- se enriquecerá sustancialmente, resultando difícil obtener una unidad sistemática de autores y obras. Por un lado, las órdenes religiosas continuarán su labor de análisis y estudio de sus respectivos maestros medievales. Unida a esta tarea la actividad impulsada por diversas instituciones hicieron posible el conocimiento de un mayor número de obras y autores medievales. Todo ello sin olvidar la labor investigadora realizada en las diversas universidades en las que la filosofía medieval comienza a ocupar un papel importante.

\section{1. Órdenes y Congregaciones religiosas}

La labor investigadora llevada a cabo por las distintas órdenes religiosas recibió un decidido impulso a partir de los años cuarenta. Así, los dominicos mantienen la revista «Ciencia Tomista» (editada en Salamanca) y publican además la revista «Estudios Filosóficos» (el año 1951 en Santander) y «Studium» (en Madrid el mismo año). Más reciente es la revista «Escritos del Vedat» (Valencia) editada a partir de 1970, y que ha contribuido a un mayor conocimiento de la filosofía y teología dominicana medieval.

Los Padres jesuitas, por su parte, crean la revista «Pensamiento» en 1945; los Agustinos Recoletos editan a partir de 1950 «Estudios agustinianos» y «Agustinus» desde 1956, aparte de la ya mencionada «La Ciudad de Dios». Los franciscanos continúan con «Estudios Franciscanos» e inician «Verdad y Vida» en 1943. Los PP. Mercedarios crean la revista «Estudios» en 1945. Más adelante, en 1954, los PP. capuchinos editan en Salamanca la revista «Naturaleza y gracia». Esta enumeración, no exhaustiva, puede darnos una idea del interés despertado por los estudios filosóficos (y teológicos) en el seno de las órdenes religiosas que encuentran su cauce de expresión en estas revistas especializadas. Naturalmente, gran parte de su interés se dirigirá a los maestros medievales de sus respectivas órdenes.

Así, por ejemplo, entre los dominicos, aparte de los ya mencionados Ramírez y Beltrán de Heredia, hay que destacar al P. Guillermo Fraile (1909-1970), que fue director de la revista «Ciencia Tomista» y colaborador asiduo de «Estudios filosóficos». Su trabajo investigador fue enorme. Gran conocedor de la filosofía escolástica (san Alberto, santo Tomás y Vitoria, sobre todo), su gran aportación a los estudios medievales lo constituyen sin duda los dos volúmenes dedicados a la Edad Media de su Historia de la Filosofía y el primer tomo de la Historia de la Filosofía española. Su trabajo es riguroso y extremadamente rico en datos y 
autores hispánicos de estos siglos. Junto a los dos volúmenes de los hermanos Carreras Artau, constituyen el punto de partida obligado para adentrarse en los estudios de filosofía medieval cristiana. $^{12}$

La tradición dominicana se continúa en la actualidad con Teófilo Urdánoz (recientemente fallecido, anotador de la obra de Guillermo Fraile y autor de diversos trabajos sobre Francisco de Vitoria), Victorino Rodríguez (editor de las obras del P. Ramírez), Vicente Forcada (autor de una reciente traducción de los tratados filosóficos de san Vicente Ferrer), Adolfo Robles (historiador de la teología y filosofía medieval, que colaboró en la edición crítica de las obras de santo Tomás, publicando también diversos manuscritos inéditos del Doctor Angélico), Abelardo Lobato, etc.

En la Orden de La Merced sobresale el P. Vicente Muñoz Delgado (1922-1995). Su abundante producción, fruto de una incansable labor investigadora, se centra en el estudio de la lógica medieval. El P. Muñoz es un profundo conocedor de la lógica matemática moderna. Realizó sus estudios de Lógica en la Universidad de Lovaina, Claveland (Ohio) y en la Georgeton University de Washington. ${ }^{13}$ Ha desempeñado su labor docente en la Pontificia Universidad de Salamanca. La principal aportación de este autor es el redescubrimiento de la riqueza contenida en los tratados lógicos medievales tanto en el campo de la semántica y semiótica, como en la lógica formal. De este modo, los estudios de lógica medieval contrastan la imagen del pensamiento medieval como una mentalidad preponderantemente «mística» o «irracional», en donde el conocimiento fiducial interfería negativamente en el desarrollo del discurso racional. Al contrario; precisamente la mejor intelección de los misterios revelados constituía un poderoso estímulo para la adecuada clarificación del nuestro pensamiento. Por otro lado, Muñoz Delgado ha trabajado en la rehabilitación de la lógica escolástica delimitándola claramente de la lógica neoescolástica tomista, considerablemente más pobre en contenidos que la que llegó a cristalizar durante los siglos XIII y XIV en las universidades europeas. En este sentido resulta obligada la mención a un trabajo suyo aparecido en 1975 en la revista Cuadernos Salmantinos de Filosofía titulado «Introducción al Patrimonio Escolástico de la lógica». De su abundante producción destacamos: La lógica nominalista en Salamanca (1510-1530), Lógica formal y filosofía en Domingo de Soto, y Lógica matemática y lógica filosófica.

La investigación realizada por los PP. jesuitas ha sido, ciertamente, de enorme importancia en el conjunto de los estudios medievales. Es necesario, por tanto, citar los nombres de Manuel Alonso, Miguel Batllori, Eusebio Colomer, Ramón Ceñal y Teodoro de Andrés.

Manuel Alonso y Alonso (1893-1965) se especializó, desde el comienzo de su labor investigadora, en la filosofía medieval musulmana, campo donde sus publicaciones han sido reco-

12 Sobre la vida y extensa producción de Guillermo Fraile, véase Díaz Díaz, G., Hombres y documentos de la filosofía española (III), cit. pp. 278-280.

13 Para una exposición de la obra de Muñoz Delgado, cfr. López Quintás, A., Filosofía española contemporánea, cit., pp. 693-700. 
nocidas a nivel internacional. Sus estudios sobre la filosofía del siglo XII (Gundisalvo, Juan Hispano y el Liber de Causis) son ya clásicos e imprescindibles para todo estudio sobre esta época. Así mismo, a él debemos la edición, con introducción y notas, de las obras filosóficas de Pedro Hispano en tres volúmenes, comenzada en 1941 y finalizada en 1952, bajo el patrocinio del Instituto Luis Vives, al que me referiré posteriormente. ${ }^{14}$

Por su parte, Ramón Ceñal Lorente (1907-1977) fue un reconocido especialista dentro del campo de la filosofía española. Su investigación responde a la necesidad de redescubrir la tradición filosófica hispánica e insertarla en el contexto intelectual europeo. Con este fin se propuso continuar la labor iniciada por Menéndez Pelayo, publicando en 1948 su libro Filosofía española y portuguesa de 1500-1650. Repertorio de fuentes hispánicas. Llevó a cabo, además, una serie de importantes monografías sobre filósofos hispánicos de la Segunda Escolástica (Sebastián Izquierdo, Pedro de Fonseca, Juan Caramuel, etc.) consagrando numerosos trabajos a la filosofía de Francisco Suárez y su influjo en la filosofía moderna. ${ }^{15}$

La investigación medievalista de Miguel Batllori (1909) abarca tanto el ámbito teológico como el filosófico, habiendo centrado su atención principalmente en la cultura catalana. Entre su ingente labor deben mencionarse sus numerosos estudios sobre Ramón Llull y el lulismọ; a él debemos la edición de las obras del Doctor Iluminado y su traducción al catalán, sin olvidar sus trabajos sobre Arnau de Vilanova, Duns Escoto, y ya en el ámbito renacentista los estudios sobre Lorenzo Valla, Pico de la Mirándola y del Humanismo en la Corona de Aragón de los siglos XIV y XV. Ha abordado también el estudio de autores de la Segunda Escolástica, particularmente Francisco Suárez y Pedro Luis Beuter. ${ }^{16}$

Eusebi Colomer Pons (1923), que últimamente ha centrado su atención en el pensamiento alemán moderno y contemporáneo, ha hecho aportaciones al campo de la filosofía medieval, de indudable valor. Su actividad como medievalista comenzó estudiando el pensamiento de Ramón Llull y su influencia en el pensamiento europeo medieval y renacentista. Fruto de esa labor es su libro Ramón Llull, Nicolás de Cusa y. Juan Pico de la Mirándola. De la Edad Media al Renacimiento (publicado en 1975) en el que muestra las raíces lulianas del pensamiento del Cusano y su influencia en la filosofía renacentista. Pero esta obra no es más que la culminación de otras publicaciones sobre estos autores, aparte de dedicar también otros estudios a la obra de Raimundo Martí, Arnau de Vilanova y Ramón Sibiuda. ${ }^{17}$

Por último, dentro de los PP. jesuitas mencionaré la aportación realizada por Teodoro de Andrés (1927-1983) en el campo de la filosofía medieval; su formación medievalista se realizó

14 Puede consultarse, sobre la vida y obra del P. Alonso, Díaz Díaz, G., Hombres y documentos de la filosofia española (I), cit., pp. 179-181, y Gómez Nogales, S., «Nota bio-bibliográfica» en Pensamiento 97-99 (1969). pp. 5-20.

15 Sobre el pensamiento y obras de Ramón Ceñal, cfr. Díaz Díaz, G., Hombres y documentos de la filosofía española (II), cit. pp. 306-308.

16 Sobre la producción medievalista de Batllori, cfr. Díaz Díaz; G., Hombres y documentos de la filosofía española (I), cit., pp. 364-370.

17 Acerca de la importante producción medievalista de E. Colomer, cfr. Díaz Díaz, G., Hombres y documentos de la filosofía española (II), cit., pp. 364-370. 
bajo la dirección de especialistas como Étienne Gilson y Paul Vignaux, entre otros. Su prematura desaparición no impidió una fecunda reinterpretación de la controvertida figura de Guillermo de Ockham; acudiendo a los textos originales, y en abierto diálogo con los especialistas de la obra del Venerabilis Inceptor, elaboró El nominalismo de Guillermo de Ockham como filosofía del lenguaje (1969), que es una obra ya clásica para toda investigación sobre Ockham, como lo demuestran los estudios posteriores fuera del ámbito hispano. ${ }^{18}$ Como complemento de estos estudios, dedicó también particular atención al conocimiento intuitivo y místico, habiendo publicado varios artículos en la revista «Crisis» en los años 71 y 72 . Un tema preferido de su investigación fue el estudio de los orígenes de la filosofía medieval, reelaborando una interpretación histórico-filosófica en lạ que se subraya el papel central que ocupó la revelación judeo-cristiana en la evolución del pensamiento occidental. ${ }^{19}$

Quedan por citar otros autores de esta misma orden, cuyos trabajos continúan siendo interesantes contribuciones a la filosofía medieval. Así, por ejemplo, los dos volúmenes de Clemente Fernández sobre Los filósofos medievales. Selección de textos y la selección de autores y textos de Los filósofos del Renacimiento y Los filósofos escolásticos de los siglos XVI y $X V I I$, dentro de su proyecto de recolección de los autores y obras más importantes de la historia de la filosofía. Por otro lado, destacan las publicaciones de Juan Pegueroles, autor de diversos estudios sobre la filosofía agustiniana que culminan en su obra San Agustín. Un platonismo cristiano.

Entre los Agustinos Recoletos se encuentra el profesor Saturnino Álvarez-Turienzo O.S.A.R. (1920). Insertado dentro de la corriente del agustinismo cristiano ha centrado sus trabajos -muy numerosos- en la obra de san Agustín y su influencia en el pensamiento medieval y moderno. Sobre todo ha investigado el alcance del concepto agustiniano de persona en diálogo con las concepciones contemporáneas, como lo demuestran sus obras principales: El cristianismo y la formación del concepto de persona y San Agustín y los personalismos contemporáneos. En la actualidad desarrolla su labor docente e investigadora en la Universidad Pontificia de Salamanca, de la que ha sido decano de la Facultad de Filosofía. Ha sido también director de las revistas «La Ciudad de Dios» y «Cuadernos Salmantinos de filosofía», desde la que se han dado a conocer numerosos trabajos de tema medieval. ${ }^{20}$ En este mismo ámbito intelectual enmarcamos a José Oroz Reta O.S.A.R., autor de numerosísimos trabajos sobre el pensamiento agustiniano, destacando entre otros su libro San Agustín y la cultura clásica

18 Pocos años antes de la publicación del trabajo de T. de Andrés, el profesor Sergio Rábade realizó un interasante estudio sobre el mismo autor que resulta también imprescindible, a pesar de sus limitaciones, para adentrarse en la filosofía del XIV, si bien con valoraciones distintas a las realizadas por de Andrés. Cfr. Rábade Romeo, S., Guillermo de Ockham y la filosofía del siglo XIV, CSIC, Madrid 1966.

19 Para una exposición más detallada de la obra de este autor, cfr. Díaz Díaz: G., Hombres y documentos de la filosofia española (I), cit. 290-292.

20 Para una exposición detallada de la importante obra de Álvarez Turienzo, cfr. Díaz Díaz, G., Hombres y documentos de la filosofía española (I), cit.. pp. 241-246; Guy. A., Historia de la filosofía española. Anthropos, Barcelona 1985. pp. 387-390; también el volumen especial de «Cuadernos Salmantinos de Filosofía» 17 (1990) dedicados a su pensamiento filosófico. 
(1963), así como la edición y traducción de las Etimilogías isidorianas, aparecida en los años 82-83.

En la Universidad Pontificia de Salamanca ha desarrollado su labor Enrique Rivera de Ventosa (1913), de la orden de los Hermanos Menores Capuchinos, cuya producción resulta indispensable a la hora de evaluar los estudios de la filosofía medieval hispánica. Es un pensador original, pero ante todo -como acertadamente señala Alain Guy- un renombrado historiador de la filosofía medieval, discípulo de Gilson. A él debemos valiosos artículos sobre san Agustín, Duns Escoto y santo Tomás, así como la monografía sobre los Supuestos filosóficoreligiosos de las pruebas de la existencia de Dios en San Buenaventura (1973). ${ }^{21}$

En conclusión, se puede resumir la actividad investigadora de este grupo de autores ligados a las distintas órdenes religiosas, señalando que encontramos una serie de medievalistas centrados en la filosofía tomista y en la Segunda Escolástica, junto a otros que dedican sus esfuerzos a la figura intelectual de Ramón Llull, sin olvidar a aquellos que prestan atención a otros autores como Guillermo de Ockham o al Beato Duns Escoto, un tanto olvidados en la historiografía anterior.

\subsection{C.S.I.C., academias y asociaciones filosóficas}

Junto a la labor desarrollada por las órdenes religiosas, encontramos también la contribución decisiva de una serie de instituciones que han hecho posible la maduración de los estudios medievales en nuestro país. Así, por ejemplo, y ya desde comienzos de siglo, hemos de contar con la Asociación Española para el Progreso de las Ciencias, que en 1908 publicó los primeros volúmenes de la Historia de la filosofía española elaborados por Bonilla San Martín, y a partir de 1939 facilitó la publicación del resto de las obras (Carreras Artau, Cruz Hernández y Marcial Solana).

Si Bonilla San Martín, como afirmé anteriormente, fue el precursor de los estudios medievales, los hermanos Carreras Artau han sido los grandes continuadores de ésa tarea. La producción de ambos se encuentra más centrada desde un principio en la filosofía medieval, contrariamente a la obra de Bonilla que es el reflejo de una labor de humanista, más interesado por las diversas realizaciones culturales (arte, literatura, etc...) que de la filosofía en sentido estricto. La producción de cada uno de los hermanos Carreras Artau merece un tratamiento por separado.

Tomás Carreras Artau (1879-1954) comenzó su actividad intelectual —al igual que hiciera Bonilla - en el campo de la jurispridencia, y a través de ella comenzó a interesarse por temas de la conciencia nacional española. Desde esta perspectiva centró su investigación en la filosofía catalana y, después, en la filosofía española en general. Los primeros trabajos estric-

21 Sobre el pensamiento y obra de Rivera de Ventosa puede consultarse Guy: A., Historia de la filosofía española, cit.: pp. 390-392; Sáez, E. y Rossell, M., Repertorio de Medievalismo Hispánico III(1955-1985), Ed. El Albir; Barcelona 1983. pp. 383-384. Recientemente la revista Anthropos ha dedicado un número monográfico a este autor: «Enrique Rivera de Ventosa, un pensador actual. Una visión dialógica de la cultura», Anthropos 1992. 
tamente filosóficos tuvieron por objeto la obra de Ramón Sibiuda, Francesc Eiximenis y Ramón Llull, interés que mantuvo a lo largo de su vida. Sin embargo, como adelanté anteriormente, su mayor aportación fue la llevada a cabo junto a su hermano Joaquín sobre la filosofía cristiana de los siglos XIII al XV; a dicha obra me referiré más adelante. ${ }^{22}$

La obra de Joaquín Carreras Artau (1894-1968) se encuentra centrada casi desde el primer instante en la historia de la filosofía, junto a estudios sobre fundamentación del Derecho. En 1923 leyó la tesis doctoral que llevaba por título Ensayo sobre el voluntarismo de Juan Duns Escoto. Su actividad como profesor se inició en la Universidad de Barcelona en 1937; en 1951 fue nombrado catedrático de Historia de la Filosofía. Su labor docente se completaba con una producción investigadora sumamente rica, centrándose especialmente en autores como Duns Escoto, Arnau de Vilanova, Ramón Llull y el lulismo. ${ }^{23}$

En 1929 la Asociación Española para el Progreso de las Ciencias convocó la continuación de la Historia de la filosofía española que comenzara en su día Bonilla San Martín. Los hermanos Carreras Artau se encargaron de la realización del proyecto, que contaba con dos volúmenes que comprendían la filosofía cristiana de los siglos XIII al XV, e hicieron su aparición entre los años 1939 y 1943. Esta obra continúa siendo un punto de referencia obligado para toda investigación sobre la filosofía medieval hispánica. Sigue en líneas generales el plan previsto por Bonilla, aunque introduce algún cambio de enfoque. En efecto, la visión de Bonilla de la filosofía medieval española parece explicar el pensamiento filosófico peninsular como fruto del «genio nacional», resaltando el carácter específico de la filosofía española. El enfoque de los Carreras Artau, en cambio, tiende a concebir la filosofía hispánica de este periodo en una relación más estrecha con el conjunto del pensamiento medieval europeo. Sin embargo, la gran atención prestada a la filosofía lulista nos revela que se encuentra también muy presente el intento de subrayar la peculiaridad del pensamiento peninsular, frente a la filosofía que por entonces se desarrollaba en las universidades europeas.

Junto a la Asociación Española para el Progreso de las Ciencias, fue decisivo el impulso que se dio a la investigación desde el Consejo Superior de Investigaciones Científicas, sobre todo a raíz de la creación en el año 1940 del «Instituto de Filosofía Luis Vives» y, posteriormente, con la «Schola Lullistica Maioricensis», que cristalizó en la publicación de la «Revista de Filosofía» en 1942 y con los «Estudios Lulianos» en el 57. La creación del «Instituto de Filosofía Luis Vives» tenía por objeto la investigación filosófica, sobre todo centrada en el pensamiento hispánico abierto, no obstante, a las nuevas corrientes filosóficas europeas.

En la práctica resultó ser un elemento aglutinador de estudiosos de procedencia e intereses muy dispares, pero que hicieron posible la revitalización de los estudios de filosofía en

22. Una exposición detallada de la vida y obra de este autor puede consultarse Díaz Díaz, G., Hombres y documentos de la Filosofía española (II), cit., pp. 177-180.

23 Un tratamiento detenido de la obra y vida de este autor se encuentra en Díaz Díaz, G., Hombres y documentos de la filosofía española (II), cit., pp. 173-177; López Quintás, A., Filosofía española contemporánea, cit.. 495-502. 
nuestro país. Allí se encontraron Manuel Mindán Manero (primer presidente del Instituto), Sergio Rábade (historiador de la filosofía, pero más centrado en el pensamiento moderno), el ya mencionado Santiago Ramírez, Roberto Saumells (que se especializará en cuestiones de filosofía de la naturaleza), Antonio Millán Puelles y otros más que de un modo u otro se adentraron en obras y autores medievales desde diversas perspectivas. Haré mención de algunos de ellos: Ángel González Álvarez, Jesús García López, José María Rubert Candau y Sebastián Garcías Palau.

Ángel González Álvarez (1916-1991), catedrático de Metafísica de la Universidad Complutense de Madrid, no se puede considerar medievalista en sentido estricto, pero no podemos olvidar la fuerte formación tomista que se encuentra presente a lo largo de toda su producción, ya sea en el campo de la Teología Natural y Metafísica, como en sus publicaciones acerca de la historia de la filosofía en general. Algo similar podemos añadir de Jesús García López, catedrático de la Universidad de Murcia y Navarra, cuyas publicaciones sobre la filosofía de santo Tomás de Aquino (Estudios de metafísica tomista, o Doctrina de Santo Tomás sobre la verdad, entre otros), muestran su profundo conocimiento de la obra del Aquinate. Junto a Santiago Ramírez, expone de modo más fidedigno algunas nociones centrales de la filosofía de santo Tomás, como es la noción de analogía, un tanto empobrecida en los comentadores escolásticos.

En este mismo círculo de investigadores aglutinados en torno al «Instituto Luis Vives» destaca la labor medievalista llevada a cabo por el profesor José María Rubert Candau, reconocido especialista de la filosofía española del siglo XIV, el cual centró su investigación en la figura de Guillermo Rubió. Sus publicaciones al respecto son imprescindibles a la hora de evaluar la aportación hispánica a la filosofía medieval europea, destacando sobre todas ellas $L a$ filosofía del siglo XIV a través de Guillermo Rubió (1952) que representa un acabado fruto de su labor investigadora precedente.

Por otro lado, la fecunda labor investigadora de Sebastián Garcías Palau (1908), Rector de la «Schola Lullistica Maioricensis», se ha centrado en el pensamiento de Ramón Llull del que es un profundo conocedor, como lo demuestran sus trabajos: Ramón Llull y el Islam y Ramón Llull en la historia del ecumenismo. En 1957 fue nombrado director de la recién creada revista «Estudios Lulianos». En 1960 se organizó bajo su dirección el I Congreso Internacional de Lulismo, así como el Iİ Congreso celebrado en 1976.2+

Bajo el impulso y estímulo del «Instituto Luis Vives» se creó en 1962 la «Asociación Española para el Estudio de la Filosofía Medieval», que en ese mismo año celebró el primer congreso en el que participaron entre otros Joaquín Carreras Artau, Sebastián Garcías Palou, Saturnino Álvarez Turienzo, José María Rubert Candau, Manuel Alonso y Eusebi Colomer. Sus actividades no se extendieron más de diez años, ya que al concluir el V Congreso Internacional de Filosofía Medieval, celebrado en Madrid en 1972, se disolvió dicha asocia-

24 Cfr. Díaz Díaz, G., Hombres y documentos de la filosofía española (III), cit., pp. 434-437. 
ción. ${ }^{25}$ Posteriormente se ha reconstituido la Sociedad de Filosofía Medieval, por iniciativa e impulso de Joaquín Lomba Fuentes.

Bajo el impulso del «Instituto Luis Vives» se creó la «Sociedad Española de Filosofía». En el seno de esta sociedad surgieron interesantes aportaciones a los estudios medievales. Sin embargo, la labor del «Instituto Luis Vives» sólo perduró hasta mediados de los años setenta, cuando desapareció como tal. Fueron años de crisis en los estudios de la filosofía hispánica.

En la actualidad, el «Consejo Superior de Investigacienes Científicas» (C.S.I.C) continúa prestando atención, a través del «Departamento de Historia Medieval del Centro de Estudios Históricos», a la producción filosófica medieval en nuestro país. En este marco se encuadra la labor de Horacio Santiago-Otero, gracias a la cual se están dando a conocer nuevos manuscritos de autores y obras medievales que se encuentran en las bibliotecas españolas. Así, por ejemplo, éste último ha publicado ya el segundo volumen de los Manuscritos de autores medievales hispanos; de Santiago-Otero citaremos también su reciente monografía sobre Fe y cultura en la Edad Media, y otros trabajos sobre teología y filosofía medieval. No podemos olvidar el trabajo de Luciano Pereña y Antonio García y García (Corpus Hispanorum de Pace), publicado por el C.S.I.C. en 1975.

Para completar el cuadro, necesariamente limitado e incompleto de los medievalistas procedentes de las diversas instituciones culturales, es preciso citar la labor llevada a cabo a través de la «Biblioteca de Autores Cristianos» con la traducción y edición de las obras de autores medievales, bajo la dirección de la Universidad Pontificia de Salamanca. De este modo, en pocos años se publicó una edición latina de la Suma Teológica de santo Tomás; se realizó una edición bilingüe de la Suma Teológica y de la Suma Contra Gentiles del mismo Doctor Angélico; se editaron así mismo las obras de san Anselmo en edición bilingüe (dos volúmenes), y una selección de escritos de san Buenaventura (seis volúmenes) también en edición bilingüe. Aparte de esto se publicaron dos volúmenes de las obras de Duns Escoto, sin contar con la traducción de las obras de san Agustín, y otros Padres de la Iglesia.

\subsection{La investigación medievalista en las universidades españolas}

Trataremos ahora de la labor investigadora llevada a cabo en los ámbitos universitarios españoles, cada vez en mayor cantidad y profundidad. Si en 1975 contábamos en España con un reducido número de Facultades de Filosofía, en la actualidad se han multiplicado las mismas, creándose además diversas cátedras de Historia de la Filosofía Española en las que se comienzan a promover varias líneas de investigación dentro del ámbito medieval.

Comenzamos destacando la Universidad Pontificia de Salamanca y los profesores ya citados: Saturnino Álvarez Turienzo, Vicente Muñoz Delgado y Enrique Rivera. En la Universidad Civil de Salamanca encontramos, entre otros profesores, a Laureano Robles y Anrtonio

25 Para una extensa crónica de este primer Congreso así como de la constitución de la Asociación cfr. Gómez Nogales, P.S., «Crónica. Asociación Española para el Estudio de la Filosofía Medieval» en Estudios Lulianos, 6 (1962): pp. 327-361. 
Heredia. Laureano Robles Carcedo es autor de numerosos trabajos sobre Tomás Durán, Tomás Maluenda y otros dominicos del siglo XIII al XVII; ha trabajado también en la traducción de las obras de Tomás de Aquino, así como acerca de la polémica sobre la posible influencia del Pugio Fidei de Ramón Martí en el Doctor Angélico. Por su parte, Antonio Heredia Soriano, si bien no se ha especializado en la filosofía medieval, sus investigaciones sobre la historia de la filosofía han contribuido a acrecentar el conocimiento del pensamiento hispánico medieval. El profesor Acosta Rodríguez se ha especializado en el pensamiento de Boecio, y José Barrientos García ha dedicado diversos trabajos a autores hispánicos medievales. Recientemente ha publicado un importante estudio centrado en la Escuela de Salamanca: Un siglo de moral económica en Salamanca (1526-1629). Francisco Vitoria y Domingo de Soto.

En la Universidad Complutense de Madrid figura el catedrático de Historia de la filosofía española José Luis Abellán quien ha dedicado dos volúmenes de su obra Historia crítica del pensamiento español al periodo que nos ocupa. Destaca también Agustín-Uña Juárez, especialista en el pensamiento del siglo XIV, sobre todo en lo referente a las figuras de Walter Burleigh y Guillermo de Ockham, a los que ha consagrado una importante monografía: La filosofía del siglo XIV. Contexto cultural de Walter Burleigh. El fallecido José Antonio García Junceda, que impulsó la creación de la revista «Anales del Seminario de Historia de la Filosofía», fue un profundo conocedor de la filosofía agustiniana y de su influencia en el pensamiento medieval posterior. Por otra parte, el profesor Angel d'Ors es conocido por sus publicaciones sobre lógica medieval y escolástica dentro de nuestra Península. En la Universidad Autónoma enseña historia de la filosofía medieval el profesor Mariano Brasa Díez.

La Universidad de Barcelona cuenta con una larga tradición de estudios dedicados a la filosofía medieval. Anteriormente he mencionado a los hermanos Carreras Artau y a los estudios en torno al pensamiento de Ramón Llull. Ahora me referiré brevemente a la Escuela Tomista de Barcelona, que nació bajo el impulso del P. Ramón Orlandis y cristalizó en la figura de Jaime Bofill, primer catedrático de Metafísica de la Facultad de Filosofía y Letras. Los principios metafísicos de inspiración tomista, aunque en Bofill encontremos también un fondo agustiniano, serán las señas de identidad de los autores que posterioremente se incorporarán a esta Escuela. Bofill fundó en 1956 la revista «Convivium», que hasta su desaparición en 1976 estuvo marcada por un interés particular por la filosofía escolástica. ${ }^{26}$

En la cátedra de Metafísica de Barcelona le sucedió su discípulo, el profesor Francisco Canals Vidal, consolidándose así esta Escuela de pensamiento tomista. En la amplia producción investigadora del Doctor Canals aparece reflejado su interés por el pensamiento filosófico medieval. Sobre todo ha centrado su atención en las grandes síntesis teológico-filosóficas cristianas (san Agustín, san Buenaventura, santo Tomás, Escoto y Suárez). Fruto de esta labor son el manual de Historia de la Filosofía medieval y la antología de Textos de los grandes filósofos. Edad Media; ambos se encuentran ya en su tercera edición. ${ }^{27}$ Dentro de la misma

26 Para una exposición completa y resumida de la historia y autores de esta escuela, cfr. Forment Giralt, E., «La Escuela tomista de Barcelona» en Verbo, n. 267-268 (1988): pp. 1119-1134. La revista «Convivium» ha comenzado de nuevo a publicarse, iniciándose la segunda época de dicha revista. 
Escuela de Barcelona, el profesor Eudaldo Forment Giralt ha escrito numerosos trabajos sobre el pensamiento cristiano medieval; es un gran conocedor del pensamiento agustiniano y tomista, siendo uno de los más notables especialistas en la obra de Cayetano y otros comentadores de la Segunda Escolástica, como lo demuestra su documentada monografía sobre Persona y modo sustancial. ${ }^{28}$. Con el impulso del profesor Forment se ha constituido en Barcelona la sección española de la Sociedad Internacional de Tomás de Aquino (S.I.T.A), que ha celebrado el primer Congreso Internacional. ${ }^{29}$ Por otra parte, el profesor Josep Maria Petit Sullá se ha especializado en temas de filosofía de la naturaleza, desde una perspectiva tomista. En el ámbito de esta misma Universidad, Josep Manuel Udina i Cobo figura como un gran conocedor de la filosofía lulista.

Vamos a reseñar brevemente la labor investigadora llevada a cabo en la Universidad de Navarra, que ha contribuido de una manera u otra al auge de los estudios medievales en España. Allí fue donde desarrolló gran parte de su investigación el profesor Jesús García López, citado anteriormente, el cual fue durante muchos años director de la revista Anuario Filosófico. En estos últimos años, el profesor Josep Ignasi Saranyana ha investigado la evolución filosófica del pensamiento bajomedieval: Buenaventura, Tomás de Aquino y Ockham, así como la influencia del joaquinismo en la Baja Edad Media. Fruto de su labor docente es el manual de Historia de la Filosofía medieval, del que recientemente ha publicado su cuarta edición. Destacan también las publicaciones del profesor José Luis Fernández Rodríguez, que se ha especializado en temas de metafísica y teoría del conocimiento en santo Tomás y en autores de la Segunda Escolástica, habiendo publicado una importante monografía sobre El ente de razón en Francisco de Araujo. Por su parte, Ángel Luis González, gran conocedor de la metafísica tomista (Ser y participación en Tomás de Aquino), ha trabajado sobre la metafísica nominalista de Guillermo de Ockham, y en la obra de Nicolás de Cusa. Finalmente, el profesor Juan Antonio Paniagua lleva trabajando varios años en la edición crítica de las obras de Arnau de Vilanova. ${ }^{30}$

En otros centros universitarios españoles se está trabajando sobre el pensamiento medieval. Así, por ejemplo, Juan Fernando Ortega Muñoz (Málaga) se ha especializado en filósofos

27 Sobre la obra medievalista de Canals puede consultarse Díaz Díaz, G., Hombres y documentos de la filosofía española (II), cit., pp. 100-102.

28 Acerca de la obra de Eudaldo Forment, cfr. Hombres y documentos de la filosofía española (III), cit., pp. 258-260.

29 Otros jóvenes profesores se encuentran insertados en esta escuela, como Ignacio Guiu, Francesc Torralba, Margarita Mauri, Francisca Tomar, etc..

30 En los últimos años han ido apareciendo, bajo la orientación de los profesores de la Universidad de Navarra, obras encaminadas a reinterpretar el pensamiento medieval desde una perspectiva moderna: Segura, C., La dimensión reflexiva de la verdad. Una interpretación de Tomás de Aquino; Haya Segovia. F., Tomás de Aquino ante la crítica. La articulación trascendental de conocimiento y ser; Dolby Múgica, M.C., El hombre es imagen de Dios. Visión antropológica de San Agustín; García Cuadrado. J.A., Hacia una semántica realista. La filosofía del lenguaje de San Vicente Ferrer; Miralbell Guerín. I.. El dinamicismo voluntarista de Duns Escoto; Moya Cañas, El principio del conocimiento en Tomás de Aquino; Sellés Duader. J.F., Conocer y aniar: estudio de las operaciones del entendiento y voluntad según Tomás de Aquino. 
medievales andaluces. En la Universidad de Málaga encontramos a Manuel J. Peláez, autor de una excelente monografía sobre el pensamiento de Eiximenis. Por su parte, Jesús de Garay (Sevilla) ha publicado diversos artículos sobre Duns Escoto y Eckhart; Alfonso García Marqués (Murcia) ha estudiado la incidencia del pensamiento árabe en la síntesis filosófica de Tomás de Aquino; a él debemos también la edición de diversas obras del Aquinate. En la Universidad de Zaragoza, el profesor Jorge M. Ayala Martínez ha centrado sus estudios en los filósofos aragoneses medievales.

Varias universidades pontificias están contribuyendo actualmente desde el campo de la Historia de la Teología a la investigación medieval en nuestro país. Así, por ejemplo, Evangelista Vilanova, profesor de la Facultad de Teología de Cataluña, ha editado dos importantes volúmenes de la Historia de la Teología medieval, al igual que Melquíades Andrés (Universidad de Extremadura), que se ha centrado en la Historia de la Teología de la Segunda Escolástica. No podemos dejar de mencionar a Josep Maria Perarnau, quien desde 1982 dirige el «Arxiu de textes catalans antics», en el que se han publicado diversas obras de la filosofía medieval catalana (Eiximenis, Arnau de Vilanova, etc.).

\section{ESTUDIOS HISPÁNICO-MEDIEVALES EN EL EXTRANJERO}

Para finalizar, pasaré a señalar de modo esquemático los principales autores y estudios que se han llevado a cabo fuera de nuestras fronteras sobre la filosofía cristiana de la España Medieval. Podemos decir que la filosofía hispánica medieval ha despertado un interés relativo entre los medievalistas europeos. Si bien no podemos hablar en sentido estricto de especialistas del pensamiento medieval hispánico, sí podemos resaltar algunos estudios de los más reconocidos medievalistas europeos que han tratado desde perspectivas diversas aspectos y autores hispánicos, dentro del marco general más amplio de investigación sobre el pensamiento medieval en Occidente.

Comenzaré por los medievalistas franceses. Acerca de la época isidorina destaca la obra en dos volúmenes de Jacques Fontaine: Isidore de Séville et la culture classique dans l'Espagne visigotique, publicada en 1959. Por otra parte, medievalistas como Étienne Gilson, Henry Bédoret, Pierre Mandonnet o Roger de Vaux han estudiado a lo largo de este siglo diversos aspectos de la filosofía española del siglo XII. Más concretamente se han preocupado por la trasmisión de las obras de Aristóteles en el mundo occidental, principalmente a través de las escuelas de traductores. En este sentido son ya clásicos sus trabajos sobre la obra de Domingo Gundisalvo o sobre el Liber de Causis y su influjo posterior. Por su parte, H.D. Simonin ha dedicado a Pedro Hispano significativos estudios. Littré, Haureau y Longpré estudiaron diversos aspectos del pensamiento de Ramón Llull. Debemos mencionar también los trabajos de Jean-Henry Probst, centrados en el pensamiento de Llull y el lulismo, como lo demuestran sus libros Caractère et origine des idées du Bienhereux R. Llulle y Le lullisme de 
R. Sebonde, ambos publicados en 1912. Más tarde, tenemos el libro de Reváh sobre el pensamiento de Ramón Sibiuda: Une source de la spiritualité péninsulaire au XIV siècle: la «théologie naturelle» de R. Sebonde (1953).

Mención aparte merece el hispanista francés Alain Guy, profesor de la Universidad de Toulouse-Le Mirail, el cual ha dedicado varias páginas de sus obras Les philosophes espagnols d'hier et d'aujourd'hui (dos volúmenes publicados en 1956) e Histoire de la philosophie espagnole (1983) a los filósofos Ramón Llull, Sibiuda, Arnau de Vilanova, Anselm Turmeda y a la Segunda Escolástica. De ambas obras existen traducciones castellanas. En el ámbito francés destaca así mismo Louis Sala-Molins, autor de diversos estudios sobre Ramón Llull y de la traducción francesa de algunas obras lulianas. Ha dedicado atención a autores hispanos medievales como Eymerich y más en general a la historia del pensamiento catalán medieval. ${ }^{31}$ Por su parte, el profesor de la Universidad de Grenoble y especialista en el pensamiento luliano Armand Llinarés, es autor de un interesante trabajo titulado Raymund Lulle, philosophe de l'action y de una reciente monografía sobre el Doctor Iluminado.

En ámbito medievalista alemán, mencionaré a George Büllow, que preparó las ediciones críticas de dos obras originales de Domingo Gundisalvo: De inmortalitate animae (1897) y De processione mundi (1927), y algún trabajo aislado pero significativo de Martin Grabmann ${ }^{32}$ sobre la lógica de Pedro Hispano. Dentro todavía del marco del medievalismo alemán sobresale la obra de Franz Ehrle, Arnold von Vilanova als Politiker und Laientheologe (1909). Este autor dedicó algunos trabajos a la Escuela de Salamanca, al igual que Albert Lang (autor de una importante monografía sobre el pensamiento teológico de Melchor Cano).

Ramón Llull es el filósofo español que mayor interés ha suscitado fuera de nuestras fronteras. La tradición de estudios sobre el Doctor Iluminado, que comenzara ya en la época renacentista y moderna, ha sido continuada en Francia, Inglaterra e Italia, pero sobre todo en Alemania, país donde ha recibido la mayor atención investigadora. Allí es donde Friedrich Stegmüller creó el «Raimundus Llullus-Institut», que depende de la Facultad de Teología de Friburgo en Brisgovia, y que ha contado con numerosos especialistas de la obra luliana como Stöhr, Madre, Riedlinger, entre otros.

Friedrich Stegmüller (1902-1981) fue profesor de Teología medieval de la Universidad de Friburgo en Brisgovia. A él debemos numerosos trabajos sobre el pensamiento de Ramón Llull. A finales de los años cincuenta inició la edición crítica de la Opera Omnia Latina del Doctor Iluminado. Se ha encargado también de las voces dedicadas a filósofos hispanos de la Segunda Escolástica del Lexikon fiir Theologie und Kirche, publicado entre los años 1957-1964, así

31. Sobre la obras de Sala-Molins, cfr. Repertorio de Medieralismo Hispánico (IV), cit.. p. 18.

32. Sobre la amplia labor científica de Grabmann puede consultarse OTT, L.; «La obra científica de Martín Grabmann» en Scripta Theologica, 13 (1981), pp. 239-246. 
como del Repertorium Biblicum Medii Aevi, publicados por el C.S.I.C. ${ }^{33}$ En la preparación de la edición de las obras latinas de Llull ha colaborado el catedrático de la Universidad de Bamberg, Johannes Stöhr, al que debemos también diversos artículos sobre la obra filosófica y teológica de Ramón Llull publicados en la revista «Estudios Lulianos». Algo similar debemos afirmar de Alois Madre, catedrático de la Universidad de Friburgo en Brisgovia, colaborador de la edición latina de la Opera luliana, al igual que Helmut Riedlinger (Universidad de Friburgo en Brisgovia) ${ }^{3+}$ Dentro todavía de los medievalistas alemanes es obligada la mención de Klaus Reinhardt (Universidad de Trier), especialista en historia de la teología medieval. Ha colaborado con Stegmüller en el Repertorium Biblicum Medii Aevii, y con el profesor Santiago-Otero en la publicación de numerosos estudios sobre la obra de Pedro de Osma y Pedro Alfonso. Por otro parte, ha publicado diversos trabajos sobre los comentarios a la Biblia de autores de la Segunda Escolástica hispánica.

En el ámbito anglosajón destacamos los estudios sobre el pensamiento de Francesc Eiximenis llevados a cabo por el profesor David J. Viera (Tennesse Technological University), mas la publicación de manuscritos inéditos y edición crítica de los mismos realizada por $\mathrm{C}$. Wittlin (Universidad de Saskatchewan en Canadá). Albert G. Hauf (Universidad de Cardiff) ha llevado a cabo una importante labor de recuperación de textos inéditos de Eiximenis. Por otro lado, es clásica la edición y el estudio crítico de las Summulae Logicales de Pedro Hispano que realizó Joseph P. Mullaly en 1945, ${ }^{35}$ mientras que el profesor canadiense J.A. Trentman ha publicado diversos estudios y una primera edición crítica de los tratados filosóficos de san Vicente Ferrer. Allison Peers, en Inglaterra, ha dedicado trabajos al pensamiento de Ramón Llull.

De los medievalistas italianos destacaré a Rossi y sus estudios sobre Ramón Llull; a Carlo Giacon, autor de varios artículos y de una amplia monografía sobre la Segunda Escolástica, publicada en 1944, en la que presta especial atención a los pensadores hispánicos.

Podemos concluir resumiendo la investigación medievalista sobre el pensamiento hispano medieval señalando que son fundamentalmente dos los focos de atención de los medievalistas europeos. Por un lado, el pensamiento filosófico catalán con numerosos trabajos sobre Anselm Turmeda, Arnau de Vilanova y, sobre todo, Ramón Llull; por otro lado, son notorias las publicaciones llevadas a cabo en torno a las principales figuras de la Segunda Escolástica española (Francisco Vitoria, Domingo de Soto, Melchor Cano, etc.).

33 Para la obra de Stegmüller puede consultarse el Repertorio de Medievalismo Hispánico (IV), cit., p.245. Puede consultarse también el artículo de Macken, R., «El Repertorium Biblicum de Friedrich Stegmüller», en Scripta Theologica, 16 (1984), pp. 857-861.

34 Para una exposición de las obras de estos autores pueden consultarse las voces correspondientes del Repertorio de Medievalismo Hispano, cit.

35 Posteriormente I.M. Bochenski publicó otra edición crítica de las Summulae Logicales, a las que hay que sumar la más reciente de Lambert M. De Rijk: del año 1972, con un interesante estudio preliminar, así como la primera traducción castellana realizada por Mauricio Beuchot en 1986. 
Esta apretada panorámica sobre la actividad medievalista durante el siglo XX habrá de ser, sin duda, revisada y ampliada. Autores y obras relevantes han quedado en el tintero y habrán de ser rescatadas del olvido. Sin embargo, espero que esta sintética visión de conjunto pueda servir como punto de partida para abordar con mayor amplitud y profundidad la historiografía sobre la filosofía cristiano-medieval en nuestro país.

José Ángel García Cuadrado

Facultad Eclesiástica de Filosofía

Universidad de Navarra

E-31080 PAMPLONA (NAVARRA) 